\title{
Latitudinal aerosol size distribution variation in the Eastern Atlantic Ocean measured aboard the FS-Polarstern
}

\author{
P. I. Williams, G. McFiggans, and M. W. Gallagher \\ SEAES, University of Manchester, Manchester, UK \\ Received: 6 November 2006 - Published in Atmos. Chem. Phys. Discuss.: 11 December 2006 \\ Revised: 14 March 2007 - Accepted: 30 March 2007 - Published: 15 May 2007
}

\begin{abstract}
Aerosol size distribution measurements from $0.03 \mu \mathrm{m}$ to $25 \mu \mathrm{m}$ diameter were taken at ambient humidity aboard the German research vessel, FS-Polarstern, during a transect from Bremerhaven in northern Germany, to Cape Town in South Africa across latitudes $53^{\circ} 32^{\prime} \mathrm{N}$ to $33^{\circ} 55^{\prime} \mathrm{S}$, denoted cruise number ANT XXI/1. The data were segregated according to air mass history, wind speed and latitude. Under clean marine conditions, the averaged size distributions were generally in good agreement with those reported previously for diameters less than $0.5 \mu \mathrm{m}$ and can be approximated by two log-normal modes, with significant variation in the mean modal diameters. Two short periods of tri-modal behaviour were observed. Above $0.5 \mu \mathrm{m}$, there is indication of a limit to the mechanical generation of marine aerosol over the range of wind speeds observed $\left(\sim 1.7-14.7 \mathrm{~m} \mathrm{~s}^{-1}\right)$. A new technique to determine the errors associated with aerosol size distribution measurements using Poisson statistics has been applied to the dataset, providing a tool to determine the necessary sample or averaging times for correct interpretation of such data. Finally, the data were also used to investigate the loss rate of condensing gases with potentially important consequences for heterogeneous marine photochemical cycles.
\end{abstract}

\section{Introduction}

Marine atmospheric aerosol plays a key role in a number of climate processes. Aerosol particles directly affect the radiative balance of the atmosphere by absorbing and scattering in-coming solar radiation (Haywood and Boucher, 2000) and indirectly affect it by impacting on the microphysical properties of marine clouds (Ramanathan et al., 2001). Understanding these processes is important in determining climate

Correspondence to: P. I. Williams

(paul.i.williams@manchester.ac.uk) change (Houghton et al., IPCC 2001). Although the production rate per unit area of marine aerosols may be small compared to industrial regions, the oceans cover $70 \%$ of the Earth's surface making them a significant global source of atmospheric particulates. In addition to their direct and indirect effects on radiative forcing, marine aerosols are also known to significantly affect the chemistry of the atmosphere through heterogeneous and multiphase processes (von Glasow et al., 2002; Keene, 1998). For example, the activation of bromine from sea-salt aerosol particles has been postulated as a heterogeneous cycling mechanism with significant atmospheric implications (Sander et al., 2003). Modelling results predict significant impacts of Reactive Halogen Species (RHS) on marine photochemistry (Sander et al., 1996; Vogt et al., 1999; McFiggans et al., 2000; von Glasow et al., 2004) through ozone depletion, perturbation to the $\mathrm{NO}_{\mathrm{x}}$ and $\mathrm{HO}_{\mathrm{x}}$ ratio and coupling to the sulphur cycle. The direct participation of marine aerosol in radiative forcing and the control of multiphase chemical processes by available deliquesced particles thus provides the motivation for measurement of ambient marine aerosol.

Of fundamental importance to the quantification of these processes is the aerosol size distribution, which spans several orders of magnitude in both number and size (Fitzgerald, 1991; O’Dowd et al., 1997). Mechanical generation of particles by bubble bursting is the largest primary source of seasalt aerosol number concentrations (Blanchard and Woodcock, 1957; Blanchard, 1963; Spiel, 1998). Air bubbles entrained into the ocean by wind and subsequently bursting at the sea surface generate film and jet aerosol, with peak modal diameters in the sub and super micron size ranges respectively. At winds speeds greater than approximately $8 \mathrm{~ms}^{-1}$, droplets can be ripped directly from wave crests, generating large particles known as spume droplets (Monahan et al., 1983; Smith et al., 1989). The number concentration of particles in these modes is a function of the wind speed, and the

Published by Copernicus Publications on behalf of the European Geosciences Union. 


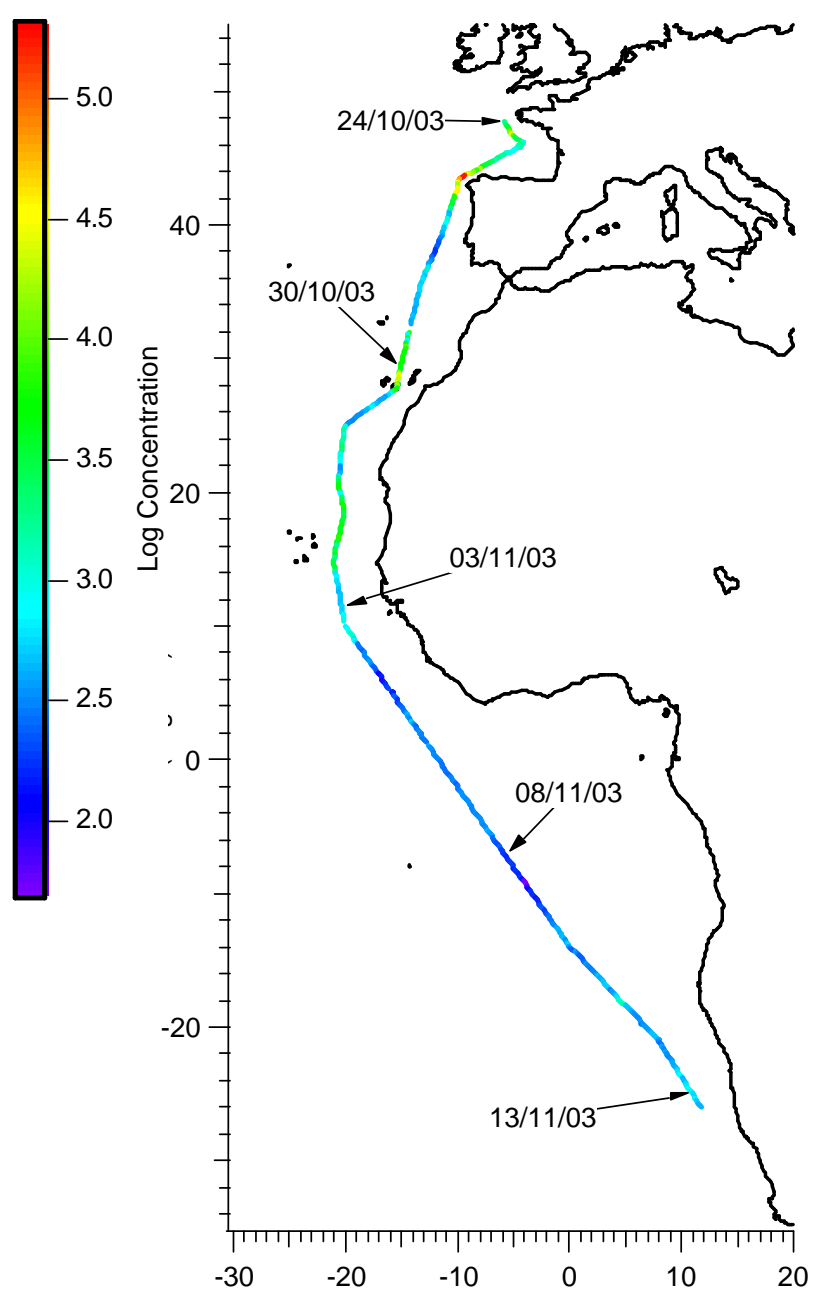

Fig. 1. Ship track from cruise ANT XXI/1 October-November 2003 coloured to the total number concentration $\left(D_{p}>30 \mathrm{~nm}\right)$.

concentration is often expressed in the following form:

$\log C \approx a U_{10}+b$

where $\mathrm{C}$ is the concentration, $\mathrm{U}$ is the wind speed at $10 \mathrm{~m}$ and $a$ and $b$ are constants for a given size or mode (See O'Dowd et al., 1997, and references therein).

The composition of the marine aerosol is not pure sea-salt. Particles smaller than $0.1 \mu \mathrm{m}$ in diameter in the Aiken mode $\left(D_{p}=20-100 \mathrm{~nm}\right)$ and nucleation mode $\left(D_{p}<10 \mathrm{~nm}\right)$ were thought to be predominately sulphate, however more recent studies have shown that particles below $100 \mathrm{~nm}$ also contain sea-salt (Nilsson et al., 2001; Mårtensson et al., 2003; Geever et al., 2005; Clarke et al., 2006) as well as significant levels of organic material (Hoffman and Duce, 1976; O'Dowd et al., 2004; Coe et al., 2006). In a study by Cavalli et al. (2004), it was proposed that the increase in organic content of clean marine Aitken mode aerosol was linked to an increase in biological productivity. The influence of organic component mixtures on aerosol cloud activation properties is still uncertain (McFiggans et al., 2006).

This paper presents aerosol number size distribution measurements from a N-S hemisphere Atlantic ocean cruise (ANT XXI/1) which formed part of a UK NERC project "Global Marine Sources of Reactive Halogen Species". In this paper, aerosol measurement data from the cruise is compared to existing results from the marine environment and characterised as a function of wind speed. The aerosol number size distributions are then used to calculate the upper and lower limit to the mass transfer rates for HOI, an important iodine reservoir compound in the marine boundary layer. The uptake of HOI is thought to play a controlling role in iodine-mediated halogen activation from sea-salt. These mass transfer rates represent an upper limit to the HOI loss rate (assuming no solubility limit is reached and irreversible uptake occurs) and their variability is representative of that of the condensation sink for any condensing gaseous compound.

\section{Methodology}

Measurements were taken on board the German research vessel, the FS Polarstern. The Polarstern sailed from Bremerhaven in Northern Germany $\left(53^{\circ} 32^{\prime} \mathrm{N} 8^{\circ} 34^{\prime}\right.$ E) to Cape Town, South Africa $\left(33^{\circ} 55^{\prime} \mathrm{S} 18^{\circ} 22^{\prime} \mathrm{E}\right)$ in October and November 2003.

The cruise left port on the 22 October 2003 and docked in Cape Town on the 14 November. The ship stopped once offshore from Las Palmas, Grand Canaria, on the 30 October for several hours to transfer scientists and equipment aboard. Figure 1 shows a track plot of the course from the 24th onwards, the point from which valid data was collected thereafter. The data set from the 24th onwards is nearly continuous comprising over $460 \mathrm{~h}$ of measurements. As well as the aerosol instrumentation (see below), there was supporting meteorological data, GPS and sea surface characteristics from the ship's data systems, GC-MS air sample analyses from the University of York, measurement of halogen radical concentrations, including $\mathrm{BrO}$ and $\mathrm{IO}$, by multi-axis DOAS (MAXDOAS) from the University of Heidelberg, water soluble gas concentrations using mist chambers from the University of Virginia and soluble particulate phase species and volatile inorganic $\mathrm{Br}$ and $\mathrm{SO}_{2}$ using a combination of filters and impactors from the University of New Hampshire. These data are the subject of further publications.

\subsection{Instrumentation}

Size distribution measurements were made using a Differential Mobility Particle Sizer (DMPS) and a GRIMM Optical Particle Counter (OPC), model 1.108. The GRIMM OPC optically sized particles from 0.3 to $20 \mathrm{um}$ in diameter and produced a particle size histogram every $6 \mathrm{~s}$, using the intensity 
of scattered light at a particular angle to size the particles (Mie, 1908). The DMPS sizes charged particles by, using an electric field, selecting them for detection as a function of their electrical mobility; a technique based on the work of Knutson (1971) and Knutson and Whitby (1975). The size range covered by the DMPS was 3 to $\sim 830 \mathrm{~nm}$ diameter, although data presented here will concentrate on particles larger than $\sim 30 \mathrm{~nm}$.

The DMPS consists of two "Vienna" style Differential Mobility Analysers (DMAs) as described by Winklmayr et al., 1991. An ultrafine DMA (effective length $11 \mathrm{~cm}$ ) for particles in the size range $3.4-34 \mathrm{~nm}$ and a standard DMA (effective length $28 \mathrm{~cm}$ ) for particle sizes from $30-830 \mathrm{~nm}$. The aerosol particles are then counted using condensation particle counters (CPC). The ultrafine DMA was attached to a TSI 3025A ultrafine CPC (particle detection limit 50\% at $3 \mathrm{~nm}$ ) and the standard DMA, to a TSI 3010 CPC (particle detection limit $50 \%$ at $10 \mathrm{~nm}$ ). The DMPS was a modified version of the system described by Williams (1999). The DMAs were operated in parallel and utilised a custom built sealed, recirculating sheath air system, which was humidity controlled and filtered. The humidity control was achieved using Perma Pure Nafion ${ }^{\circledR}$ driers. These usually operate on the principle of passing air down a series of semi-permeable tubes which have a counter flow of dry air, removing water vapour. However, during this experiment, the humidity of the sheath air was controlled by using moist air in the counter flow allowing the sheath air to be dried $(\mathrm{RH}<10 \%)$ or set to ambient. The temperature and relative humidity of the sheath air flow was monitored as it entered and exited the DMA.

The sheath and aerosol inlet flows were recorded by measuring the differential pressure across flow tubes designed at the University of Manchester. The aerosol inlet flow tubes were designed to have laminar flow in order to reduce particle losses. The sheath flow was monitored and actively controlled using a software (LabView $\left.{ }^{\circledR}\right)$ driven proportional, integral, differential (PID) control module which updated at approximately $10 \mathrm{~Hz}$. The DMPS produced a spectrum once every $10 \mathrm{~min}$. An average sheath flow, aerosol flow and sheath temperature were taken during each scan and used in the subsequent data inversion routines.

The DMAs were calibrated before the cruise using NIST traceable Polystyrene Latex Spheres (PSL). The PSL diameter was plotted against the measured diameter and a linear regression was fitted to the data to produce a correction factor for each DMA.

A $2 \mathrm{~m}$ long, $11 / 4$ " OD stainless steel tube with a $\mathrm{PM}_{10}$ head (i.e. sampling all particles $10 \mu \mathrm{m}$ in diameter and smaller) was mounted on A deck of the ship, approximately $20 \mathrm{~m}$ above sea level. This was used as the main inlet for the DMPS. The inlet was fixed on the starboard side of the vessel, approximately $1 / 3$ of the ship's length from the bow. The inlet was pumped at $\sim 171 \mathrm{~min}^{-1}$ to maintain the size transmission characteristics of the $\mathrm{PM}_{10}$ head and the DMPS sub- sampled from the main draw with a $1 / 4$ " OD stainless steel pipe. The sub-sample was brought inside via a port hole to an air conditioned corridor, where it was introduced to the DMPS approximately $2.5 \mathrm{~m}$ from the main draw. Calculations of the diffusional losses down the sub-sample, using the methodology as described in Baron and Willeke (2001, pp 579-581), showed there was 50\% transmission of $4 \mathrm{~nm}$ particles, increasing to $100 \%$ transmission for $9-10 \mathrm{~nm}$ particles.

The GRIMM OPC was mounted directly to the top of the $2 \mathrm{~m}$ DMPS inlet, below the $\mathrm{PM}_{10}$ head. The sample inlet of the GRIMM was extremely short, $\sim 8 \mathrm{~cm}$, with a cowl to protect it from wind-ramming and rain ingress. Tests carried prior to the underway measurements found that this arrangement did not produce any significant losses, when compared to measurements with no inlet system attached. The GRIMM was mounted externally and so recording data very close to the ambient RH.

One of the parameters recorded by the ship's data logging systems was the relative wind direction. This allowed the data to be filtered for potential contamination from the ship's exhaust. Data that was associated with a relative wind direction from $135^{\circ}$ to $225^{\circ}$ was removed, as it could contain aerosol from the main exhaust.

\subsection{Error analysis}

A new method was used to calculate the error associated with each concentration data point in the DMPS spectrum using an approach based on Poisson statistics. Poisson statistics are applied to systems with a large number of test subjects, but with low probabilities of observing the desired outcome. DMA's sample all aerosol, but only select charged particles in a very narrow band of mobility, where the probability of charging an individual particle is low. For a given number of particles counted, $n$, in one event (per mobility channel per sample time), the standard error associated with $n$ is $n^{1 / 2}$ (Taylor, 1982). This error is then propagated through the DMPS inversion algorithms to yield an error in $d N / d \log D_{p}$, the concentration of particles at a given diameter normalised to the logarithm of the bin spacing. This approach involves correcting for the shape of the transfer function of the DMA, the flow rate of the particle counter and the size dependent effects of multiple charging. The effects of multiple charging can be accounted for using the approximation of Wiedensohler et al. (1988). For example, taking a typical polluted (clean) event and denoting it as polluted (clean), then a raw particle count of 730 (3) at a size of $30 \mathrm{~nm}$ yields a value for $d N / d \log D_{p}$ of 3675 (12.8) with an error of $143(8.8)$, (values in $\mathrm{cm}^{-3}$ ). These calculations are based on use of a standard DMA with a TSI 3010 CPC and an integration time of 6 seconds. This then provides the uncertainty in the measurement based on the counting statistics associated with each data point in time. When averaging the data over different sampling times or meteorological conditions, these errors 

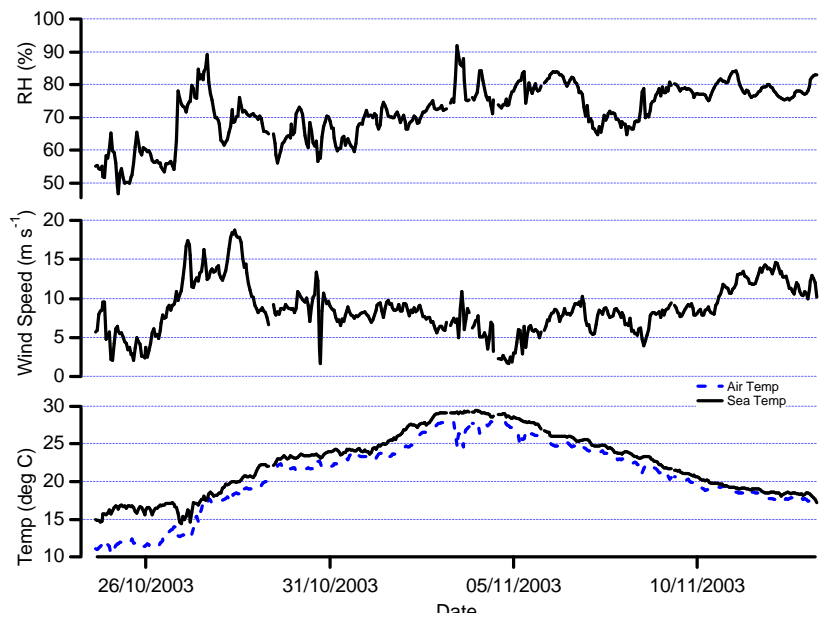

Fig. 2. Relative humidity (RH), wind speed and air and sea temperature from cruise ANT XXI/1.

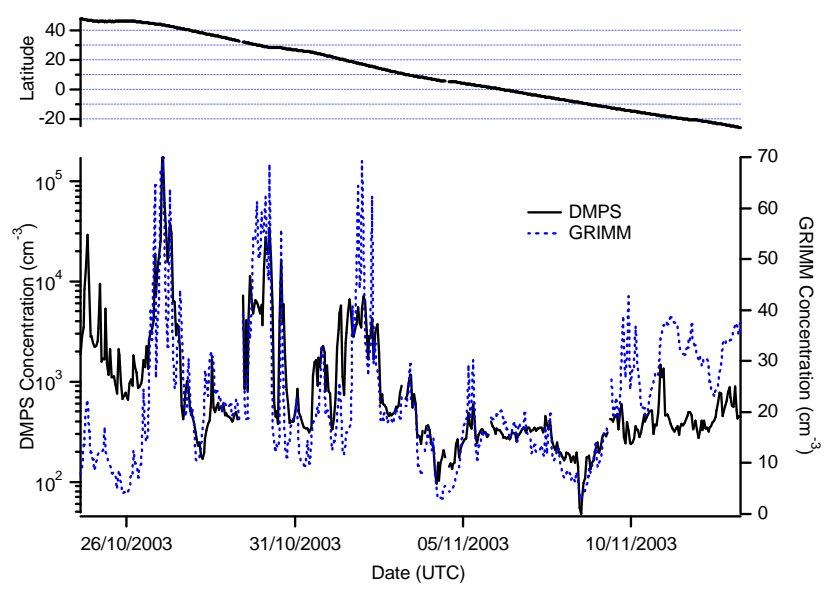

Fig. 3. Time series of the latitudinal variation and total number concentrations from the DMPS and GRIMM.

were combined to give an uncertainty associated with the average measurements, as well as the statistical variance within the averaged data.

\subsection{Meteorology}

The relative humidity $(\mathrm{RH})$, air temperature ( $T$, and sea temperature) and wind speed $(U)$ from cruise ANT XXI/1 can be seen in Fig. 2. The RH rarely peaks above 90\%, with the only exceptions being on the 27 October and 3 November. Throughout the cruise, the RH was mainly below $80 \%$.

The air temperature (and sea temperature) increased steadily from the Northern Hemisphere as the ship steered south from $11^{\circ} \mathrm{C}$ to $28^{\circ} \mathrm{C}$ at approximately $9.6^{\circ} \mathrm{N}$, thereafter decreasing to just under $17^{\circ} \mathrm{C}$. The wind speed was variable throughout and will be discussed further in the next section. A detailed discussion of the meteorological conditions are presented by König-Langlo (2005).

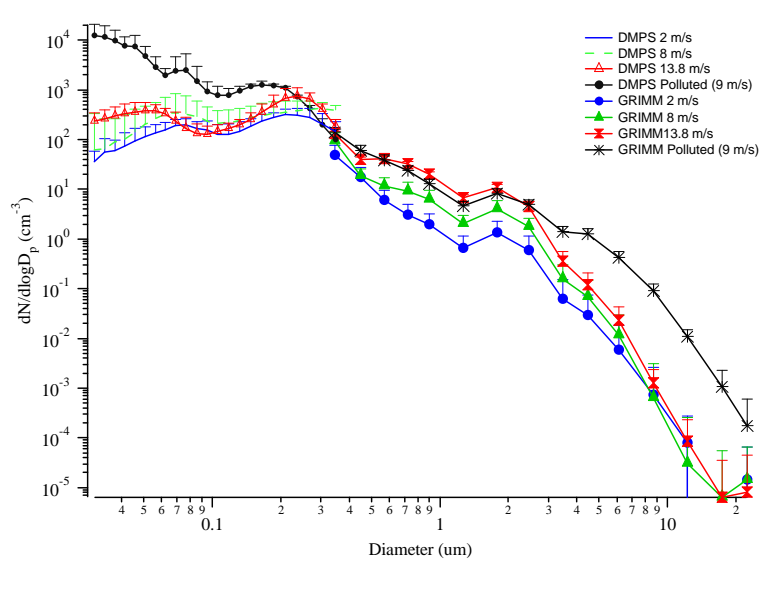

Fig. 4. Comparison of the number size distributions at different wind speeds for clean marine air and a polluted episode. The upper end of the DMPS spectra at the overlap with the GRIMM OPC are not shown for clarity, neither are the negative error bars. Errors shown are 1 standard deviation.

\section{Results}

Figure 3 shows a time series of the total particle number concentrations recorded by the GRIMM and the DMPS. The total number recorded by both instruments is highly variable throughout the campaign and is generally governed by two factors: air mass history and wind speed. For dates prior to the 3 November, the air masses originated from the North Atlantic and European regions, representing clean marine air masses or anthropogenically influenced air masses respectively. After the 3rd of November, the air was entirely marine in origin, flowing from the Eastern Atlantic. The back trajectories were generated from the online NOAA HYSPLIT transport and dispersion model, (http://www.arl.noaa. gov/ready/hysplit4.html), and were initialised at 3 heights: $100 \mathrm{~m}, 500 \mathrm{~m}$ and $1000 \mathrm{~m}$. In all cases, the lowest level had spent at least the previous $24 \mathrm{~h}$ within the boundary layer.

The highest hourly averaged concentrations were recorded on the 27 October at 02:00 am and were $172757.0 \mathrm{~cm}^{-3}$ and $69.9 \mathrm{~cm}^{-3}$ for the DMPS and GRIMM respectively. The lowest hourly averaged values were $47.7 \mathrm{~cm}^{-3}$ and $2.8 \mathrm{~cm}^{-3}$ for the DMPS and GRIMM on the 8 November at 12:00 p.m.

The differing conditions identified by the back trajectories had very different influences on the observed size distributions, examples of which are shown in Fig. 4. For a clean marine air mass example, the average number size distribution exhibited 4 modes; a mode in the size range less than $0.1 \mu \mathrm{m}$, two modes in the size range $0.1-1 \mu \mathrm{m}$ and a mode in the super micron range, all of which are statistically significant from one another. The two smallest modes agree well with the concept of the marine aerosol as widely reported by other authors (see Fitzgerald, 1991 and O'Dowd et al., 1997 for reviews). The mean modal diameter of the supermicron mode reported by others is variable, with diameters 
ranging from $\sim 1 \mu \mathrm{m}$ (Exton et al., 1985) to $\sim 7 \mu \mathrm{m}$ (O'Dowd et al., 1997). The mode observed in this data set that appears around $0.6 \mu \mathrm{m}$ and develops with increasing wind speed does not fit the generally-accepted picture of the clean marine environment in the works cited above. Furthermore, from 02:00 on the 9th to 09:00 on the 10th, there are two periods when the number size distribution below $0.5 \mu \mathrm{m}$ is trimodal, with mean modal diameters of $0.073 \mu \mathrm{m}, 0.145 \mu \mathrm{m}$ and $0.334 \mu \mathrm{m}$, which again does not fit the currently accepted picture of the marine aerosol number size distributions cited in other works, and is not seen when averaging the data as a function of wind speed. This indicates that the distribution shape is transient with statistically significant trimodality below $500 \mathrm{~nm}$ on timescales shorter than $1 \mathrm{~h}$. One possible explanation for this behaviour is that there could be an external mixture of hygroscopic and less hygroscopic aerosol. The humidity in the DMPS was run at ambient RH and it could be that the tri-modality represents an ensemble of aerosol with 2 different compositions and growth factors. The instrumentation was not available to test this hypothesis.

Data obtained from the ultra-fine DMA was intermittent, so there is limited information in the sub $30 \mathrm{~nm}$ size range. However, during periods when data were available, no evidence for a nucleation mode was seen in the clean marine air masses. For the polluted case, the sub $0.1 \mu \mathrm{m}$ mode is greatly enhanced due to anthropogenic sources. During the clean marine cases, the number in these modes is dependant on the wind speed. Figure 4 shows the size distributions from the DMPS and GRIMM averaged over different wind speed regimes from 3 November onwards. This period was chosen as it represents the clearest cases of "clean" marine air. It can be seen that the number concentration in all the modes increases with increasing wind speed. The most noticeable development however is in the mode centred around $0.6 \mu \mathrm{m}$.

Figure 5 shows a time series of the mean modal diameters from the 3rd of November onwards for cases when the sub $0.5 \mu \mathrm{m}$ number size distribution is bi-modal. The mean modal diameters are quite variable for the two modes, with an average, maximum and minimum of $0.064,0.089$ and $0.039 \mu \mathrm{m}$ respectively for the sub $0.1 \mu \mathrm{m}$ mode and 0.220 , 0.352 and $0.154 \mu \mathrm{m}$ respectively for the mode $>0.1 \mu \mathrm{m}$. Koponen et al. (2002) provides a very useful comparison to the modal structure of submicron aerosol, not only because it covers an almost identical route, but also because it uses nearly identical methodologies for measuring the aerosol size distribution. There are some factors that need to be highlighted that introduce an uncertainty in making a direct comparison. The major difference between this data and the Koponen et al. (2002) data is the relative humidity in the DMAs. The relative humidity was kept at less than $20 \%$ in Koponen et al., whereas in this data set it was maintained at ambient. Comparing data from similar areas the Aitken geometric mean diameter is given as $\sim 40 \mathrm{~nm}$ in Koponen et al. (2002), whereas $64 \mathrm{~nm}$ was more representative of the current dataset. For the accumulation mode, Koponen et

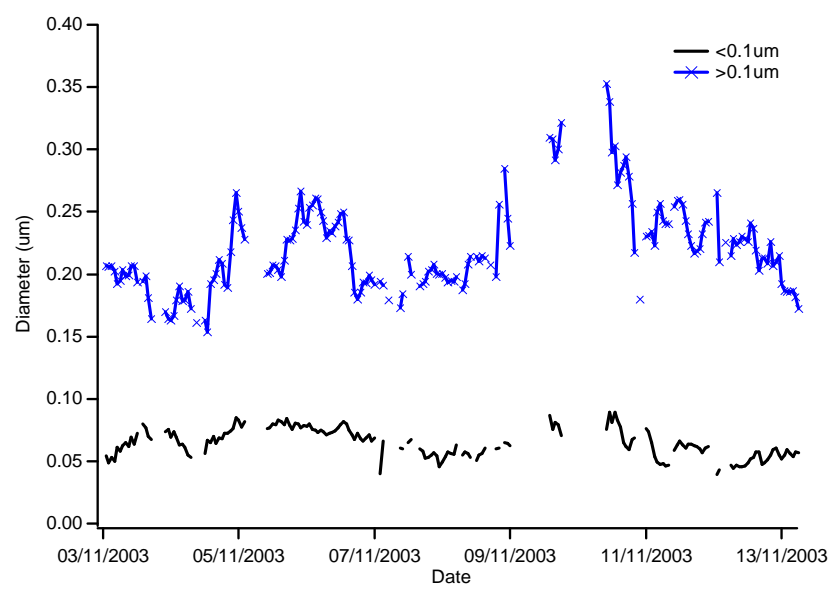

Fig. 5. Time series of the modal diameters from the DMPS when the size distribution below $0.5 \mu \mathrm{m}$ is bi-modal.

al. (2002), reports a value of $\sim 176 \mathrm{~nm}$ whilst that in the current study is $220 \mathrm{~nm}$. At $70 \%$ (80\%) $\mathrm{RH}$, a $40 \mathrm{~nm}$ pure sea salt particle will have a growth factor (GF) of 1.78 (1.91) and for $176 \mathrm{~nm}$ pure sea salt, a GF of 1.81 (1.99) (ADDEM model, David Topping, private communication). Using these growth factors to grow the Koponen et al., Aitken mean mode diameter yields a mean modal diameter of $71.2-76.4 \mathrm{~nm}$, which is similar to the sizes in this study. It is possible that the particles were not entirely efflorescenced in the drying process reported in the Koponen et al. (2002) study. A better comparison would be to compare $\mathrm{D}_{\mathrm{p} \text { Williams }}$ with $\mathrm{D}_{\mathrm{pKoponen}}$ $\times \mathrm{GF}_{70-80 \%} / \mathrm{GF}_{20 \%}$, where the subscript states the $\mathrm{RH}$ of the GF. The ADDEM model predicts a $\mathrm{GF}_{20 \%}$ of 1.38 and 1.39 for a $40 \mathrm{~nm}$ and $176 \mathrm{~nm}$ particle respectively. This yields an Aitken mean diameter of $51.6-55.4 \mathrm{~nm}$. It is likely that the particles in this size range are not pure sea salt and will have a different, probably lower GF and the value of $\mathrm{GF}_{20 \%}$ is likely an over estimation as the model is at the limit of its capability at that RH. These factors complicate the comparison.

For the accumulation mode, performing a similar task and multiplying the Koponen et al. size by the GF yields an "ambient" aerosol size of $\sim 318-350 \mathrm{~nm}$, which suggests that the geometric mean diameter is substantially larger than that reported by this study. Comparing $\mathrm{D}_{\text {pWilliams }}$ with $\mathrm{D}_{\mathrm{pKoponen}} \times$ $\mathrm{GF}_{70-80 \%} / \mathrm{GF}_{20}$, yields an ambient wet size in the range of $\sim 229-252 \mathrm{~nm}$, which is closer to the measured ambient conditions experienced on board the Polarstern. It is important to remember that at $\mathrm{RH}=20 \%$, the ADDEM model is limited to applications with $\mathrm{RH}>20 \%$ and some of the assumptions therein may be invalid and that $\mathrm{GF}_{20 \%}$ is likely to be significantly lower. However, this highlights a potential difference between the two data sets, as a shift of $30-50 \mathrm{~nm}$ or more, will have important implications on the $\mathrm{CCN}$ properties and it will also increase the condensational loss rate calculations. 


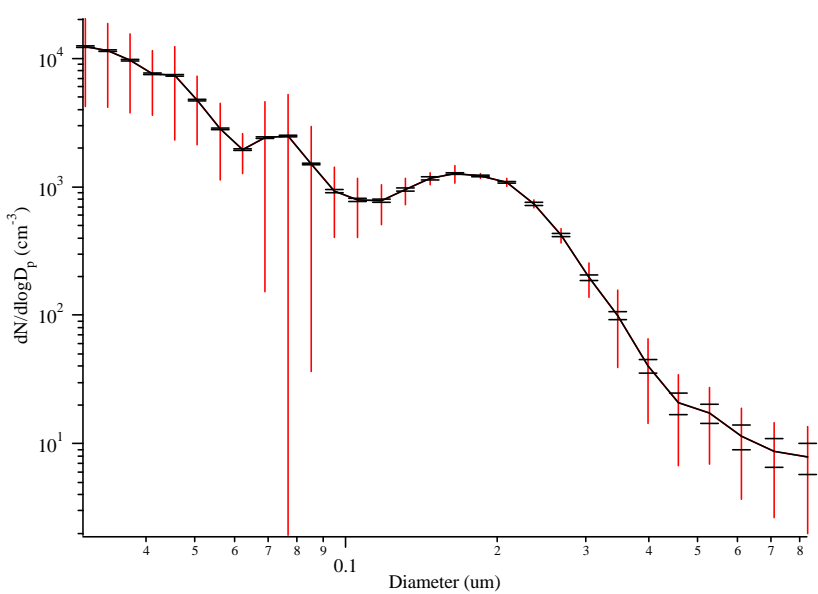

Fig. 6. Comparison of the different errors associated with the DMPS data. The vertical lines are the standard deviation over $1 \mathrm{~h}$ (26 October 2003, 1800-1900) and the bars are the errors based on Poisson statistics averaged over the same hour.

Similar results are reported in Heintzenburg et al. (2000) which compiles data from a variety of campaigns to generate a $15^{\circ} \times 15^{\circ}$ grid of marine aerosol data. In this review, a criteria is set that only data with an RH $<40 \%$ is used, hence direct comparison with this data set is problematic. Comparing data from $0^{\circ}$ to $-15^{\circ}$, the Aitken (accumulation) mode diameters are $47 \mathrm{~nm}(170 \mathrm{~nm})$ and $66 \mathrm{~nm}(222 \mathrm{~nm})$ for Heintzenberg and this study respectively.

Covert et al. (1996) present data from the mid-Pacific and describe the sub-micron aerosol size distributions recorded using a DMPS system. Although not stated explicitly, one assumes that these measurements were made a $\mathrm{RH}<40 \%$ as the data is included in the Heintzenberg review article. This makes for an interesting geographical comparison. For latitudes similar to those that this study measured, the Aikten mode is reported as having a mean diameter from $30-60 \mathrm{~nm}$, and for the accumulation mode from $150-250 \mathrm{~nm}$ which is much closer to the diameters recorded during this study at ambient RH. This would imply that the ambient size (at ambient $\mathrm{RH}$ ) of the accumulation mode aerosol is higher in the mid-Pacific than in the mid-Atlantic.

It is more difficult to perform a comparison of the number concentrations. This is complicated by two factors: Firstly, in the cited articles, the concentration is not reported with an associated wind speed, so that the contribution by particle generation mechanisns cannot be assessed. Furthermore, the Heintzenberg review states that there are gaps in the data both for compositional information and number concentration at high wind speed. Secondly there is an issue with the DMPS data at moderate to high wind speeds (see below).

The errors within associated size ranges of the DMPS data have been studied and as well as generating a statistical variance when averaging the data up to $1 \mathrm{~h}$ and over different wind speeds, an error associated with the measurement has

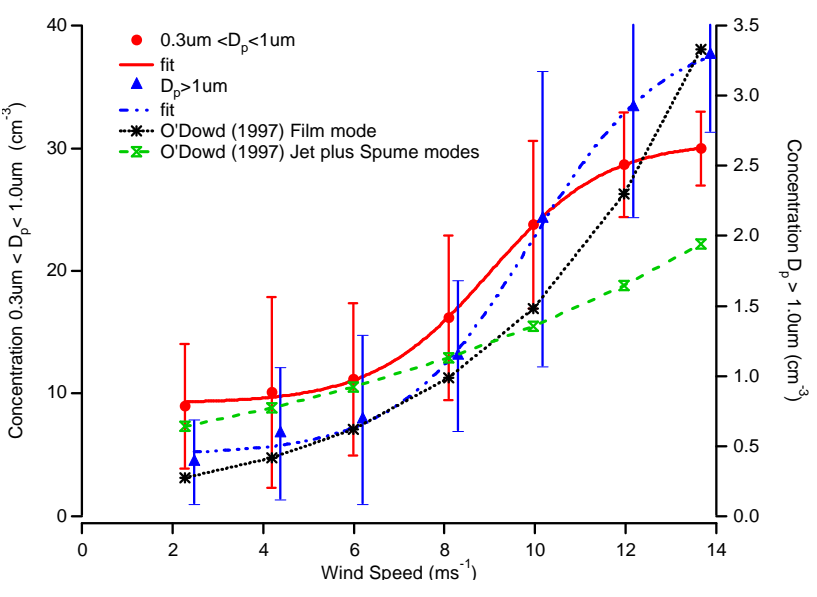

Fig. 7. Number versus wind speed from the GRIMM OPC for sizes above and below $1 \mu \mathrm{m}$. The $D_{p}>1 \mu \mathrm{m}$ has been offset on the x-axis by $+0.2 \mathrm{~m} \mathrm{~s}^{-1}$ for clarity.

been calculated using the technique described above. An example of the relative importance and magnitude of each is shown in Fig. 6, which is the same data as shown in Fig. 4. For diameters less than $\sim 0.2 \mu \mathrm{m}$, the statistical variance (i.e. the degree of scatter within the measured data set) is larger than the error due to the uncertainty in the measurement. At sizes larger than $0.15 \mu \mathrm{m}$, the measurement error begins to increase relative to the standard deviation. This is an important result as it shows that when the number concentrations are low and the sampling statistics are poor, variations in the distribution due to changing conditions may not be discernable from the uncertainty in the measurements. This technique can be used to determine a suitable sampling strategy to optimise accuracy with suitable sample or averaging times for different ambient conditions. For the data presented here as a function of wind speed, the measurement error was much smaller than the standard deviation.

A detailed analysis of the DMPS data revealed a possible concern with the sampling system. When summing the total number concentration above $\sim 350 \mathrm{~nm}$ to compare with the total number concentration from the GRIMM as a function of wind speed, the total number concentration from the DMPS did not follow the same trend as the GRIMM. In fact, the total number concentration began to decrease with increasing wind speed. Above $\sim 8 \mathrm{~ms}^{-1}$ the apparent response of the instrument declined. Integrating over more size channels (i.e. from smaller sizes) showed a similar problem but to a lesser extent. This behaviour can only be attributed to limitations in the transmission characteristics of the $\mathrm{PM}_{10}$ sample head attached to the DMPS inlet. For this reason, the DMPS data was not used in any of the parameterisation of the total number concentration as a function of wind speed given below.

Figure 7 shows the total number concentration from the GRIMM for particles in the range $0.3 \mu \mathrm{m}<D_{p}<1.0 \mu \mathrm{m}$ and 
Table 1. Fit coefficients for the number concentration as a function of wind speed. Numbers in brackets represent 1 standard deviation.

\begin{tabular}{lllll}
\hline Size Range & Base & Max & $x_{0}$ & Rate \\
\hline $0.3 \mu \mathrm{m}<D_{p}<1.0 \mu \mathrm{m}$ & $9.21(0.26)$ & $21.3(0.52)$ & $9.00(0.09)$ & $1.29(0.09)$ \\
$D_{p}>1 \mu \mathrm{m}$ & $0.44(0.07)$ & $3.02(0.18)$ & $9.71(0.21)$ & $1.45(0.19)$ \\
\hline
\end{tabular}

for $D_{p}>1.0 \mu \mathrm{m}$ as a function of wind speed from the 3 November onwards. The error bars are 1 standard deviation, which are larger than the averaged measurement errors. Also plotted are the approximate concentrations using Eq. (1), and the values taken from O'Dowd (1997), which represent the number concentrations in the modelled film and jet modes plus spume modes. Fitted to the Polarstern data is a sigmoid function of the form:

$$
y=\text { base }+\frac{\max }{1+\exp \left(\frac{\mathrm{x}_{0}-x}{\text { rate }}\right)}
$$

where base is the value at small $x, \max$ is the value at large $x, x_{0}$ is the value of $x$ at which $y$ is (base+max)/2 and rate is the rise rate. The values for each fit are given in Table 1 below. The largest relative increase is in the larger size range, with concentrations increasing from 0.38 to $3.29 \mathrm{~cm}^{-3}$, a factor of 8.7, compared to the smaller mode with an increase from 8.9 to $\sim 30 \mathrm{~cm}^{-3}$, a factor of just over 3 . What is also significant is the apparent plateau at higher wind speeds. This differs significantly from the approximate concentrations given by O'Dowd et al. (1997), although it must be remembered that the approximation given by Eq. (1) is for pure sea-salt particles within a modelled mode, whereas the data presented here does not consider composition and is a summation over similar size ranges. However it is likely that in the size ranges covered, the vast majority of the particles are likely to be sea-spray. For particles with $D_{p}<1 \mu \mathrm{m}$, the approximation falls within the standard deviation of the measurements for all points except the first and last. For the jet plus spume modes, the approximation lies within the errors for wind speeds up to $10 \mathrm{~ms}^{-1}$, but then is lower than the values measured during the 2003 cruise. For both size ranges, the approximation from O'Dowd et al. (1997) does not show the levelling out of the concentration.

\subsection{Loss rates of trace gaseous compounds}

Using the combined DMPS and GRIMM size distribution data, the condensational loss rate, $k_{t}$ of trace gases can be calculated. The calculations are based on the equation given by Schwartz (1986):

$k t=\frac{4 \pi}{3} \int_{0}^{\infty}\left(\frac{r^{2}}{3 D_{g}}+\frac{4 r}{3 \bar{c}_{g} \gamma}\right)^{-1} r^{3} \frac{d N}{d \log r} d \log r$

where $r$ is the particle radius, $D_{g}$ is the gaseous diffusion coefficient, $c_{g}$ is the average kinetic velocity of the gas

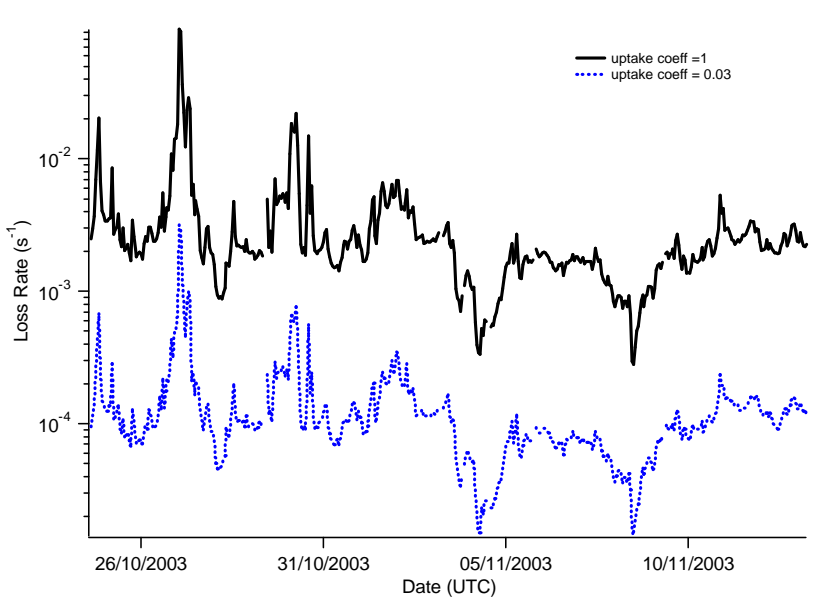

Fig. 8. Calculated loss rate $\left(\mathrm{K}_{t}\right)$ of HOI with uptake coefficients of 0.03 and 1 .

molecules and $\gamma$ is the uptake coefficient, which accounts for diffusional limitation to mass transfer to particles in the transition regime. $k_{t}$ values calculated using this expression have been shown by Sander (1999) to differ by no more than $15 \%$ from the flux matching expression of Fuchs and Sutugin (1971). The binary diffusion coefficient evaluated according to Maitland (1981) is used rather than the self diffusion coefficient. The calculations use the entire size range of the GRIMM and part of the DMPS data from $D_{p} \approx 0.03 \mu \mathrm{m}$ to $0.3 \mu \mathrm{m}$, with the caveat that the total number concentration from this instrument at high wind speeds will be underestimated. The hourly averaged temperatures and pressures were also used in the calculations thereby giving an accurate estimation of $k_{t}, D_{g}$ and $c_{g}$ under the conditions that prevailed during the cruise period. Hypoiodous acid (HOI) is a reservoir compound of reactive inorganic iodine formed from the reaction of iodine monoxide (IO) and hydroperoxy radicals $\left(\mathrm{HO}_{2}\right)$. Uptake of $\mathrm{HOI}$ to halide-containing deliquesced aerosol particles (such as sea-salt) will play a role in controlling the release of dihalogen compounds ( $\mathrm{IBr}$ and $\mathrm{ICl}$ ) and hence will modulate the level of iodine-mediated halogen activation from sea-salt aerosol. The mass transfer calculation is thus an example of the way that aerosol size distribution measurement can be used to assess the relative effects of aerosol variability on multiphase processes. The calculated mass transfer rates represent an upper limit to the HOI loss rate (assuming no solubility limit is reached and irreversible uptake occurs) and their variability is representative of that 


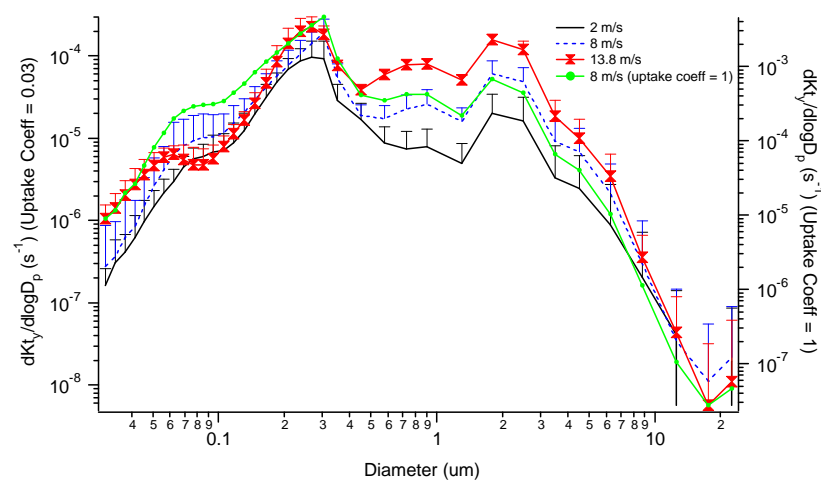

Fig. 9. Size dependant loss rate of HOI with uptake coefficients of 0.03 and 1.0 calculated from the DMPS and GRIMM OPC size distributions. Negative error bars are not shown for clarity.

of the condensation sink for any condensing gaseous compound. The calculations use the molecular weight of HOI. The range of the diffusion coefficient employed was from $2.06 \times 10^{-5}$ to $2.16 \times 10^{-5}$ and the mean molecular speed was from 204.2 to $210.7 \mathrm{~m} \mathrm{~s}^{-1}$

Figure 8 shows the time series for $\mathrm{k}_{t, \mathrm{HOI}}$ for the entire cruise. Two uptake coefficients are used, $\gamma=0.03$ and $\gamma$ $=1.00$. Using the lower value, the loss rate is limited by uptake probability, whereas a value of unity leads to significant diffusional limitation to the loss to the larger particles (hence the loss rate is not increased in proportion to the increase in accommodation coefficient). This is easily seen from inspection of Eq. (3). The value 0.03 is representative of the lower limit to uptake coefficient of hypohalous acids measured in the laboratory, whereas 1 is the maximum probability with which gases can be taken up by the aerosol surface and so provides an upper limit. The loss rate under clean marine conditions is low, as expected and the e-folding lifetime of HOI $\left(\tau=1 / \mathrm{k}_{t}\right)$ is never less than $\sim 150 \mathrm{~s}$ for the period of the 3rd onwards. From 14:00 on the 3rd of November to the morning of the 10 November, the lifetime of HOI is greater than $10000 \mathrm{~s}$ for the entire time with only two exceptions. In the limit $(\gamma=1)$, loss rates and hence lifetimes are a factor of 20-30 higher and lower, respectively.

The average loss rate as a function of size $\left(d k_{t} / d \log D_{p}\right)$ and wind speed is shown in figure 9 , with uptake coefficients of 0.03 for wind speeds of 2,8 and $13.8 \mathrm{~m} \mathrm{~s}^{-1}$ and 1.0 for $8 \mathrm{~m} \mathrm{~s}^{-1}$. Considering firstly the cases of $\gamma=0.03$, the data shows that there are two persistent sinks for the condensation of trace gases, one at $\sim 0.28 \mu \mathrm{m}$ and the other at $\sim 2.0 \mu \mathrm{m}$, and that the loss rate within these mode increases with wind speed. The data also shows that a third mode develops around $0.8 \mu \mathrm{m}$ and increases in amplitude by more than an order of magnitude over the range of wind speeds sampled. These results differ from the work of other studies. Coe et al. (2006) found similar size dependence loss rates up to diameters of $0.5 \mu \mathrm{m}$ at a coastal site, but showed the second sink extended up to $10 \mu \mathrm{m}$. O'Dowd et al. (1997), modeling the potential scavenging flux of sulphuric acid $\left(\mathrm{H}_{2} \mathrm{SO}_{4}\right)$, show the dominance of the spume mode aerosol at approximately $10 \mu \mathrm{m}$ and a second mode at approximately $1.4 \mu \mathrm{m}$. This second mode was more than a factor of 2 lower in the flux of $\mathrm{H}_{2} \mathrm{SO}_{4}$ rather than of the same order as in this study.

The case of $\gamma=1.0$ for a windspeed of $8 \mathrm{~m} \mathrm{~s}^{-1}$ shows the relative change in dependence of the condensational loss rate on the size distribution. There is an increase in the dependence of the loss rate due to the small sizes, as the process is diffusionally limited rather than limited to the uptake probability.

\section{Discussion and conclusions}

Particle number size distribution measurements and total number concentrations were made from the Northern hemisphere off the coast of France to the Southern Hemisphere approaching Cape Town, South Africa. The air masses were characterised as a function of air mass history into clean marine and anthropogenically influenced regimes and also as a function of latitude. The cases identified as clean marine were then segregated as a function of wind speed. For the clean marine cases, the classic view of a marine aerosol size distribution agreed well with the results reported by other authors at low wind speeds. However, some significant differences were also observed. Firstly, the spume mode measurements were lower in both size and number. Secondly, another mode was identified that developed with increasing wind speed at approximately $0.6 \mu \mathrm{m}$. Comparisons with other works of the sub $0.5 \mu \mathrm{m}$ mode were problematic due to differences in the RH of the systems. Growing the drier particles to ambient RH suggests that the mean geometric diameter of the sub $0.1 \mu \mathrm{m}$ mode from this study was slightly higher, but fairly close to those of other studies, but the mean geometric diameter of the second mode was possibly $30-50 \mathrm{~nm}$ or more smaller than the mean reported in other studies in similar latitudes. Furthermore, using a similar approach to data from the Pacific from Covert et al., suggests that there is a significant geographical difference between the mid-latitudes in the Pacific and Atlantic, with the Pacific having a much larger mean modal diameter. Finally, the data showed 2 short periods $(12-15 \mathrm{~h}$ ) of tri-modal behavior for aerosols smaller than $0.5 \mu \mathrm{m}$. This may be due to the humidity in the DMA separating a hygroscopic and less hygroscopic mode. This separation in the hygroscopicity of the modes could be caused by additional organic material being present in the particles.

For the majority of the project under clean marine conditions, the size distribution data for aerosols smaller than $0.5 \mu \mathrm{m}$ can be described using two log-normal distributions. However, the data collected here shows that the mean modal diameters can vary significantly. Plotting the mean modal diameter as a function of wind speed and fitting a linear re- 
gression (not shown), identified an increase in size with increasing wind speed for particles $>0.1 \mu \mathrm{m}$ and a decrease in size with increasing wind speed for the mode $<0.1 \mu \mathrm{m}$. The $R^{2}$ for these two cases were 0.06 and 0.15 respectively. It is therefore concluded that the variation in modal diameter is not sensitive to wind speed. Due to the limitations of the DMPS sampling system, the number concentration in these modes cannot be reliably quantified.

The total number concentrations as a function of wind speed for sizes $0.3 \mu \mathrm{m}<D_{p}<1.0 \mu \mathrm{m}$ and for $D_{p}>1.0 \mu \mathrm{m}$ using the GRIMM OPC were calculated. From this a parameterisation as a function of wind speed for these different sizes was generated. A sigmodal function represents the data more accurately, indicating a limit to the number of particles produced at high wind speed, but a function as defined by O'Dowd et al., 1997 could be fitted within the errors. It is unclear whether there is such a limit, but the suggestion of one requires further investigation.

A detailed approach considering the errors associated with the DMPS measurements as well as the statistical variance was employed. This was based on Poisson statistics, whereby the standard error associated with each data point is $n^{1 / 2}$, where $n$ is the number of counts in each measurement step. The standard deviation was then propagated through the DMPS data inversion routines to yield an error associated with the measurements. This revealed that under conditions where the number of particles sampled was low and averaging times were short, the error associated with the uncertainty in the measurements was comparable to the statistical variance. Using an averaging period of $1 \mathrm{~h}$ was found to be acceptable.

Although not shown, the significance of this new technique is more apparent for the ultrafine DMA and TSI UCPC 3025A data. The utrafine CPC has an internal aerosol sample flow rate of $0.031 \mathrm{~min}^{-1}$, irrespective of the total flow into the instrument. The $3010 \mathrm{CPC}$ was operated with an aerosol flow rate of $0.61 \mathrm{~min}^{-1}$ (plus a $0.41 \mathrm{~min}^{-1}$ bleed flow of particle free air). The number concentration and hence the measurement error scales directly with the aerosol flow rate. Therefore, when the two DMA's measure the same mobility, the measurement error associated with the ultrafine DMA and TSI 3025 will be a factor of 20 larger than the measurement error associated with the standard DMA and 3010 CPC.

The size distribution data was used to calculate the loss rate, $k_{t}$ of HOI with uptake coefficients of 0.03 and 1 . The calculated lifetime of halogen species such as HOI is highly variable, under clean conditions ranging from $\sim 150$ to $3500 \mathrm{~s}$ with $\gamma=1$ and from $\sim 3000$ to $70000 \mathrm{~s}$ with $\gamma=$ 0.03 . The sensitivity to uptake coefficient variability within the studied range is greater than the variability in calculated mass transfer rate due to variation in available aerosol in all but the absolute extremes of aerosol loading throughout the project and at all times in marine air (as can be seen from Fig. 8). Comparing to Coe et al. (2006) the total loss rate under clean conditions is higher and hence the lifetime shorter than in this study. However, considering the potential sampling limitations of the GRIMM OPC, the contribution from the spume mode is likely to be under-estimated and hence the total $k_{t}$ also under-estimated. The loss rate may have an effect on the potential for nucleation in the MBL. There is approximately a factor of 10 variation in the potential lose rate under clean marine conditions. Therefore, if the factors that control this variability, such as wind speed, have less than a factor of 10 influence on the production of potential precursors, then the increased potential loss rate will be likely to further suppress nucleation. If however these factors increase the available precursors at a rate higher than the potential lose rate, then this will potentially overcompensate for the increased aerosol surface area. Obviously the effect on particle formation will be dependent on the non-linearity of the nucleation process and precursor availability (e.g. gaseous oxidation needs to be considered in the production of nucleation precursors) and a direct relationship between the nucleation potential and the difference between the windspeed enhancement of condensational sink and precursor formation may not be evident.

A further consideration of the loss rate which has not been addressed is the chemical composition of the aerosol. The results of the analysis presented here have assumed a uniform uptake coefficient. In reality, the uptake coefficient is a combination of the reactive uptake of the chemical species, the accommodation coefficient and any inhibition of uptake caused by the surface. These will depend on the chemical nature of the aerosol particle, which will vary across the size range. The actual loss rate will lie within the boundaries of $\gamma=0.03$ and $\gamma=1.0$ in Fig. 9.

Acknowledgements. The author wishes to acknowledge the support and contributions from his co-authors and all those involved in the cruise. I thank O. Schrems, chief scientist on the 2003 cruise, of the Alfred-Wegener Institute for Polar and Marine Research for outstanding logistical support and providing the meteorological data presented in this paper. I would especially like to thank Captain U. Domke and the rest of the crew of the FS-Polarstern; the baptism was awesome!

Edited by: M. Kulmala

\section{References}

Allan, B. J., McFiggans, G., Plane, J. M. C., and Coe, H.: Observations of iodine monoxide in the remote marine boundary layer, $\mathrm{J}$. Geophys. Res., 105(14), 363-369, 2000.

Ayers, G. P., Ivey, J. P. and Goodman, H. S.: Sulfate and methanesulfonate in the martime aerosol at Cape Grimm. Tasmania, J. Atmos. Chem., 4, 173-185, 1986.

Blanchard, D. C.: The electrification of the atmosphere by particles from bubbles in the sea, Prog. Oceanog, 1, 171-202, 1963. 
Blanchard, D. C. and Woodcock, A. H.: Bubble formation and modification in the sea and its meteorological significance, Tellus, 9, 145-158, 1957.

Baron, P. A. and Willeke, B. (Eds.): Aerosol measurements: principles, techniques, and applications, 2nd edition, ISBN 0-47135636-0, 2001.

Cavalli, F., Facchini, M. C., Decesari, S., Mircea, M., Emblico, L., and Fuzzi, S., Ceburnis, D., Yoon, Y. J., O’Dowd, C. D., Putaud, J.-P., and Dell'Acqua, A.: Advances in characterization of size-resolved organic matter in marine aerosol over the North Atlantic, J. Geophys. Res., 109, D24215, doi:10.1029/2004JD005137, 2004.

Clarke, A. D., Owens, S. R., and Zhou, J.: An ultrafine sea-salt flux from breaking waves: implications for cloud condensation nuclei in the remote marine atmosphere, J. Geophys. Res., 111, D06202, doi:10.1029/2005JD006565, 2006.

Coe, H., Allan, J. D., Alfarra, M. R., Bower, K. N., Flynn, M. J., McFiggans, G. B., Topping, D. O., Williams, P. I., O’Dowd, C. D., Dall'Osto, M., Beddows, D. C. S., and Harrison, R. M.: Chemical and physical characteristics of aerosol particles at a remote coastal location, Mace Head, Ireland, during NAMBLEX, Atmos. Chem. Phys. 6, 3289-3301, 2006.

Covert, D. S., Kapustin, V. N., Bates, T. S. and Quinn, P. K.: Physical properties of marine boundary layer aerosol particles of the mid-Pacific in relation to sources and meteorological transport, J. Geophys. Res., 101, 6919-6930, March 20, 1996.

Exton, H. J., Latham, J., Park P. M., Perry, S. J., Smith, M. H., and Allan, R. R.: The production and dispersion if marine aerosol, Q. J. R. Meteorol. Soc., 111, 817-837, 1985.

Fitzgerald, J. W., Marine aerosols: a review, Atmos. Env., 25a(3-4), 533-545, 1991.

Fuchs, N. and A. Sutugin: Highly dispersed aerosol, in Topics in Current Aerosol Research, edited by: Hidy, G. and Brock, J., Pergamon, New York, 1971.

Geever, M., O'Dowd, C. D., van Ekeren, S., Flanagan, R., Nilsson, E. D., de Leeuw, G., and Rannik U.: Submicron Sea-spray fluxes, J. Geophys. Res. Lett., 32, L15810, doi:10.1029/2005GL023081, 2005.

Haywood, J. M. and Boucher, O.: Estimates of the direct and indirect radiative forcing due to tropospheric aerosols: a review, Rev. Geophys., 38(4), 513-543, 2000.

Hegg, D. A.: Modelling the effects of heterogeneous cloud chemistry on the marine particle size distribution, J. Geophys. Res., 97(12), 927-933, 1992.

Heintzenberg, J., Covert, D. C., and Van Dingenen, R.: Size distribution and chemical composition of marine aerosols: a compilation and review, Tellus, 52B, 1104-1122, 2000.

Hoffman, E. J. and Duce, R. A. factors influencing organic-carbon content of marine aerosols - laboratory study, J. Geophys. Res. Oceans Atmos., 81, 3667-3670, 1976.

Houghton, J. T., Ding, Y., Griggs, D. J., Noguer, M., van der Linden, P. J., Dai, X., Maskell, K., Johnson, C. A.: IPCC, 2001: Climate Change 2001: The Scientific Basis. Contribution of Working Group 1 to the Third Assessment Report of the Intergovernmental Panel on Climate Change. Cambridge University Press. Full text available at: (http://www.grida.no/climate/ipcc_tar/wg1/ index.htm).

Keene, W. and Savoie, D. L.: The pH of deliquesced sea-salt aerosol in polluted marine air, Geophys. Res. Lett., 25(12), 2181-2184,
15 June, 1998.

Knutson, E. O.: The distribution of electric charge among the particles of an artificially charged aerosol, $\mathrm{PhD}$. Thesis, Uni. Of Minnesota, Minnesota, 1971.

Knutson, E. O. and Whiteby, K. T.: Aerosol classification by electric mobility: Apparatus, theory, and application, J. Aerosol Sci., 6, 443-451, 1975.

König-Langlo, G.: Continuous meteorological surface measurement during POLARSTERN cruise ANT-XXI/1, Alfred Wegener Institute for Polar and Marine Research, Bremerhaven, PANGAEA, doi:10.1594/PANGAEA.326645, 2005.

Koponen, K. I., Virkkula, A., Hillamo, R., Kerminen, V.-M., and Kulmala, M.: Number size distributions and concentrations of marine aerosols: Observations during a cruise between the English Channel and the coast of Antarctica, J. Geophys. Res., 107(D24), 4753, doi:10.1029/2002JD002533, 2002.

O’Dowd, C. D. Smith, M. H., Consterdine, I. E., and Lowe, J. A.: Marine aerosol sea-salt, and the marine sulphur cycle: a short review, Atmos. Env., 31(1), 73-80, 1997.

O’Dowd C. D., Facchini, M. C., Cavalli, F., Ceburnis, D., Mircea, M., Decesari, S., Fuzzi, S., Yoon, Y. J., and Putaud, J. P.: Biogenically driven organic contribution to marine aerosol, Nature, 431, 676-680, 2004.

Maitland, G. C., Rigby, M., Smith, E. B., and Wakeham, W. A.: Intermolecular forces: their origin and determination., International series of monographs on chemistry 3, Oxford, Clarendon Press, ISBN 0198556411, 1981.

Mårtensson, E. M., Nilsson, E. D., de Leeuw, G., Cohen, L. H., and Hansson, H. C.: Laboratory simulations and parameterization of the primary marine aerosol production, J. Geophys. Res., 108(D9), 4297, doi:10.1029/2002JD002263, 2003.

McFiggans, G., Artaxo, P., Baltensperger, U., Coe, H., Facchini, M. C., Feingold, G., Fuzzi, S., Gysel, M., Laaksonen, A., Lohmann, U., Mentel, T. F., Murphy, D. M., O’Dowd, C., Snider, J. R., and Weingartner, E.: The Effect of Physical and Chemical Aerosol Properties on Warm Cloud Droplet Activation, Atmos. Chem. Phys., 6, 2593-2649, 2006,

http://www.atmos-chem-phys.net/6/2593/2006/.

McFiggans Plane, J. M. C., Coe, H., and Allan, B.: Observations of IO and a modelling study of iodine chemistry in the marine boundary layer, J. Geophys. Res., 105(14), 371-385, 2000.

Mie, G.: Beigrade zur optic truber medien, speziell kolloidaler metallosumgen, Ann. Physik, (4), 25, 377-446, 1908.

Monahan E. C.: The ocean as a source of atmospheric particles. In The Role of Air-Sea Exchange In Geochemical Cycling, 129$163,1986$.

Nilsson, E. D., Rannik, Ü., Swietlicki, E., Leck, C., Aalto, P. P., Zhou, J., and Norman, M.: Turbulence aerosol fluxes over the Artic Ocean 2: wind driven sources from the sea, J. Geophys. Res. Lett., 106(32), 139-154, 2001.

Ramanathan, V., Crutzen, P. J., Kiehl, J. T., and Rosenfeld, D.: Aerosols, climate, and the hydrological cycle, Science, 294, 2119-2124, 2001.

Sander, R. and Crutzen, P. J.: Model study indicating halogen activation and ozone destruction in polluted air masses transported to the sea, J. Geophys. Res., 101(9), 212-138, 1996.

Sander, R., Keene, W. C., Pszenny, A. A. P., Arimoto, R., Ayers, G. P., Baboukas, E., Cainey, J. M., Crutzen, P. J., Duce, R. A., Honninger, G., Huebert, B. J. , Maenhaut, W., Mihalopoulos, N., 
Turekian, V. C., and Van Dingenen, R.: Inorganic bromine in the marine boundary layer: A critical review, Atmos. Chem. Phys., 3, 1301-1336, 2003, http://www.atmos-chem-phys.net/3/1301/2003/.

Schwartz, S. E.: Mass-transport considerations pertinent to aqueous phase reactions of gases in liquid-water clouds, in Chemistry of Multiphase Atmospheric Systems, NATO ASI Series, G6, edited by: Jaeschke, W., Springer-Verlag, Berlin, 415-471, 1986.

Sievering, H., Boatman, J., Gorman, E., Kim, Y., Anderson, L., Ennis, G., Luria, M., and Pandis, S.: Removal of sulphur from the marine boundary layer by ozone oxidation in sea-salt aerosol, Nature, 360, 571-573, 1992.

Spiel, D. E.: On the birth of film drops from bubbles bursting on seawater surfaces, J. Geophys. Res., 103(24), 907-24,918, 1998.

Smith, M. H., Consterdine, I. E., and Park, P. M.: Atmospheric loadings of marine aerosol during a Hiberidean cyclone, Q. J. R. Meteorol. Soc., 115, 383-395, 1989.

Taylor, J. R.: An Introduction to Error Analysis: The study of Uncertainties in Physical Measurements, Oxford University Press, ISBN 0-935702-10-5, 1982.
Vogt, R., Sander, R., Von Glasow, R., and Crutzen, P. J.: Iodine chemistry and its role in halogen activation and ozone loss in the marine boundary layer: a model study, J. Atmos. Chem., 32, 375-395, 1999.

Von Glasow, Sander, R., Bott, A., and Crutzen, P. J.: Modeling halogen chemistry in the marine boundary layer -2 , Interactions with sulfur and the cloud-covered MBL, J. Geophys. Res. Atmos., D17, 4323, doi:10.1029/2001JD000943, 2002.

Von Glasow, R., von Kuhlmann, R., Lawrence, M. G., Platt, U., and Crutzen, P. J.: Impact of reactive bromine chemistry in the troposphere, Atmos. Chem. Phys., 4, 481-497, 2004, http://www.atmos-chem-phys.net/4/481/2004/.

Wiedensohler, A.: An approximation of the bi-polar charge distribution for particles in the sub-micron size range, J. Aerosol Sci., 19, 387-389, 1988.

Williams, P. I.: Construction and validation of a DMPS for aerosol characterisation, PhD Thesis, 1999.

Winklmayr, W., Reischl G. P., Lindner A. O., and Berner A.: A new electromobility spectrometer for the measurement of aerosol size distributions in the size range from 1 to $1000 \mathrm{~nm}$, J. Aerosol Sci., 22, 289-296, 1991. 